\title{
Low $\mathrm{HbA}_{1 \mathrm{c}}$ and mortality: causation and confounding
}

\author{
M. K. Rutter
}

Received: 15 May 2012 / Accepted: 8 June 2012 / Published online: 18 July 2012

(C) Springer-Verlag 2012

\begin{abstract}
This commentary provides an overview of the clinically important data linking low or lowered $\mathrm{HbA}_{1 \mathrm{c}}$ to increased total and CVD mortality in the general population, and in patients with diabetes. This sets the scene for a contribution in this issue of Diabetologia by Andersson et al (DOI: 10.1007/s00125-012-2584-3) that suggests that BMI might modify the relationship between $\mathrm{HbA}_{1 \mathrm{c}}$ and mortality in patients with type 2 diabetes. The commentary provides a framework for the interpretation of epidemiological data from observational studies and clinical trials, and it addresses the clinical implications of this work. Finally, it highlights new research that is likely to advance this field.
\end{abstract}

Keywords Cardiovascular disease $\cdot \mathrm{HbA}_{1 \mathrm{c}} \cdot$ Mortality . Type 2 diabetes

$\begin{array}{ll}\text { Abbreviations } \\ \text { ACCORD } & \begin{array}{l}\text { Action to Control Cardiovascular Risk in } \\ \text { Diabetes }\end{array} \\ \text { ADVANCE } & \begin{array}{l}\text { Action in Diabetes and Vascular Disease: } \\ \text { Preterax and Diamicron Modified Release }\end{array} \\ & \begin{array}{l}\text { Controlled Evaluation } \\ \text { Cardiovascular disease }\end{array}\end{array}$

M. K. Rutter ( $\bowtie)$

Cardiovascular Research Group,

School of Biomedicine, University of Manchester,

Core Technology Facility,

46 Grafton Street,

Manchester M13 9NT, UK

e-mail: Martin.Rutter@manchester.ac.uk

M. K. Rutter

Manchester Diabetes Centre,

Manchester Academic Health Science Centre,

Central Manchester University Hospitals NHS Foundation Trust,

Manchester, UK
The optimal $\mathrm{HbA}_{1 \mathrm{c}}$ target is uncertain for the prevention of death and cardiovascular disease (CVD) in patients with type 2 diabetes. Clinicians reading this commentary will have many high-risk patients with moderately high $\mathrm{HbA}_{1 \mathrm{c}}$ values for whom they are uncertain whether or not to intensify glucose-lowering therapy.

The objective of this commentary is to provide an overview of data relating low or lowered $\mathrm{HbA}_{1 \mathrm{c}}$ to mortality and CVD risk. This sets the scene for a valuable contribution in this issue of Diabetologia suggesting that BMI might modify the relationship between $\mathrm{HbA}_{1 \mathrm{c}}$ and mortality in patients with type 2 diabetes [1].

\section{Observational studies, $\mathrm{HbA}_{1 \mathrm{c}}$ and mortality}

Observational studies have demonstrated that hyperglycaemia is an important predictor of mortality and CVD risk [2-15], with the majority of studies showing positive linear relationships between $\mathrm{HbA}_{1 \mathrm{c}}$ and mortality or CVD risk $[4,6,7,11,14,15]$. However, several other important studies have suggested non-linear (U- or J-shaped) relationships $[3,5,8-10,12,13,16]$. Thus, the literature is inconsistent, but the issue is important because there are obvious clinical implications if low blood glucose values are the direct cause of the higher mortality risk.

It is unclear why some studies show linear relationships between $\mathrm{HbA}_{1 \mathrm{c}}$ and mortality, whereas others report nonlinear relationships. However, it may be that these differences in results are partly explained by variation in study population characteristics and by confounding factors - that is, the presence of an observed or hidden variable(s) associated with both the predictor (low $\mathrm{HbA}_{1 \mathrm{c}}$ ) and the outcome (increased mortality). Certainly, the data describing non- 
linear relationships $[3,5,8-10,12,13,16]$ may have several interpretations, and some of these studies are discussed here.

The first of these studies assessed the relationship between baseline $\mathrm{HbA}_{1 \mathrm{c}}$ and 15-year CVD risk and total mortality in people without diabetes in the Atherosclerosis Risk in Communities study [8]. The results of this study showed a J-shaped relationship between $\mathrm{HbA}_{1 \mathrm{c}}$ and mortality, and there was a suggestion of a similar relationship between $\mathrm{HbA}_{1 \mathrm{c}}$ and CVD risk. These data are particularly important because they show that the higher mortality observed with low $\mathrm{HbA}_{1 \mathrm{c}}$ values could not have been related to the presence of diabetes or the effects of its therapy (especially hypoglycaemia). Unfortunately, this study did not explore the potential causes of the J-shaped relationship between $\mathrm{HbA}_{1 \mathrm{c}}$ and mortality. In particular, it did not assess whether these relationships persisted after excluding participants with conditions such as advanced heart or kidney failure and malignancy, which could be important confounders (Fig. 1a).

A similar U-shaped relationship between $\mathrm{HbA}_{1 \mathrm{c}}$ and allcause mortality was observed in 14,099 participants without diabetes who were assessed in the National Health and Nutrition Examination Survey [10]. The higher risk associated with low $\mathrm{HbA}_{1 \mathrm{c}}$ values was attenuated, but remained significant, after adjusting for several suspected confounders, including deaths resulting from liver disease, cancer and other diseases. However, residual confounding through unmeasured variables could still explain the results.

Another important observational study showing a nonlinear relationship between baseline or average $\mathrm{HbA}_{1 \mathrm{c}}$ and mortality involved a large cohort of middle-aged and elderly patients with type 2 diabetes [9]. In this study, low $\mathrm{HbA}_{1 \mathrm{c}}$ values were associated with an increased risk of all-cause mortality and CVD events. The $\mathrm{HbA}_{1 \mathrm{c}}$ value associated with the minimum CVD and mortality risk was $\sim 58 \mathrm{mmol} / \mathrm{mol}$ (7.5\%). Whilst these 'real-life' data are welcome, they too should be interpreted with caution. Hypoglycaemia may have contributed to some of the deaths in those with low $\mathrm{HbA}_{1 \mathrm{c}}$ values, but this is hard to assess because hypoglycaemia and the causes of death were not recorded in the study. The authors explored the effects of differential prescribing of prophylactic CVD drugs by $\mathrm{HbA}_{1 \mathrm{c}}$ level, but they did not adjust for the presence of comorbid conditions that could be important confounders (Fig. 1a).

The impact of comorbidity in these relationships is well-illustrated in a large population-based study of patients with type 2 diabetes, in which low $\mathrm{HbA}_{1 \mathrm{c}}$ values $(48 \mathrm{mmol} / \mathrm{mol},<6.5 \%)$ were associated with a high risk of mortality in those with high levels of comorbidity, but not in those with lower levels of comorbidity [17].

Therefore, some [3, 5, 8-10, 12, 13, 16], but not all, prior studies have suggested that there may be a non-linear relationship between $\mathrm{HbA}_{1 \mathrm{c}}$ and mortality or CVD risk. The main concern about these data is confounding by comorbid conditions, some of which are associated with low BMI (Fig. 1a).

In this issue of the journal, Andersson and coworkers report 4-year cardiovascular outcomes and mortality in a large cohort of overweight or obese high-CVD-risk patients with type 2 diabetes enrolled in a trial of sibutramine [1]. One-fifth of the participants had $\mathrm{HbA}_{1 \mathrm{c}}$ values $<48 \mathrm{mmol} / \mathrm{mol}(<6.5 \%)$, and therefore the study was adequately powered to assess risks associated with near normal $\mathrm{HbA}_{1 \mathrm{c}}$ values. It is important to note that the study excluded some patients with comorbidities that could be important confounders (advanced heart failure or malignancy). The main finding was that the risks of cardiovascular events (the primary endpoint) and mortality were positively and linearly related to $\mathrm{HbA}_{1 \mathrm{c}}$. Importantly, there was no evidence of increased risk in individuals with $\mathrm{HbA}_{1 \mathrm{c}}$ values $<48 \mathrm{mmol} / \mathrm{mol}$ $(<6.5 \%)$. This is significant because it suggests that overweight and obese patients with type 2 diabetes may be protected from the high mortality or high CVD risk associated low $\mathrm{HbA}_{1 \mathrm{c}}$ values described in some observational studies of type 2 diabetes $[9,12,13,16]$ (Fig. 1a).

Based on these data, it is tempting to speculate that relatively fit, overweight and obese patients with type 2 diabetes might benefit especially from a low $\mathrm{HbA}_{1 \mathrm{c}}$ target. This may be an attractive hypothesis because these individuals may be insulin resistant and, therefore, less likely to experience hypoglycaemia and subsequent cardiac complications [18] compared with normal weight patients.

Data from the Action to Control Cardiovascular Risk in Diabetes (ACCORD) study showed that compared with normal weight patients, those who were obese and overweight in the standard glycaemic control arm did indeed have a lower risk of hypoglycaemia requiring medical assistance (annual incidence: BMI $<25 \mathrm{~kg} / \mathrm{m}^{2}, 1.2 \%$; BMI $25-29.9 \mathrm{~kg} / \mathrm{m}^{2}$, $0.8 \%$; BMI $\geq 30 \mathrm{~kg} / \mathrm{m}^{2}, 0.9 \%$ ) [19]. However, when an aggressive protocol-driven glucose-lowering regimen was applied, overweight and obese patients appeared to lose their protection from hypoglycaemia, with similar annual rates of hypoglycaemia in all BMI groups (2.7-2.9\%) [19]. So, in conclusion, there is little evidence in ACCORD to suggest that BMI may modify the effects of intensive glucose lowering, at least with respect to the risk of hypoglycaemia.

\section{Clinical trials, $\mathrm{HbA}_{1 \mathrm{c}}$ and mortality}

The UK Prospective Diabetes Study (UKPDS) demonstrated that, in newly-diagnosed patients with type 2 diabetes, modest $\mathrm{HbA}_{1 \mathrm{c}}$ lowering led to fewer microvascular complications and to a reduced risk of myocardial infarction in overweight metformin-treated patients [20]. There was no evidence of increased mortality associated with glucose 
Fig. 1 Epidemiological relationships between $\mathrm{HbA}_{1 \mathrm{c}}$ and mortality in observational studies (a) and in clinical trials (b) highlighting the higher risk associated with low $\mathrm{HbA}_{1 \mathrm{c}}$ values in some cohorts. $\mathrm{Rx}$, treatment a Low $\mathrm{HbA}_{1 \mathrm{c}}$ in observational studies

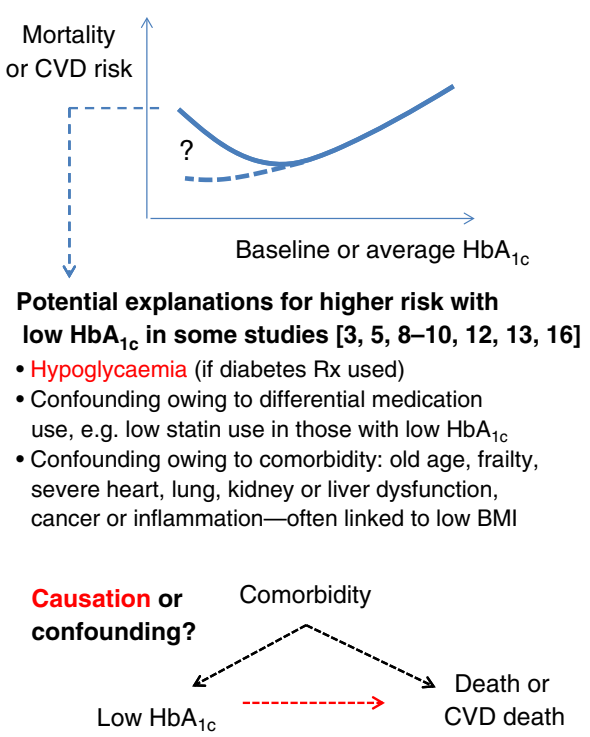

b Low $\mathrm{HbA}_{1 \mathrm{c}}$ in the ACCORD trial [27]

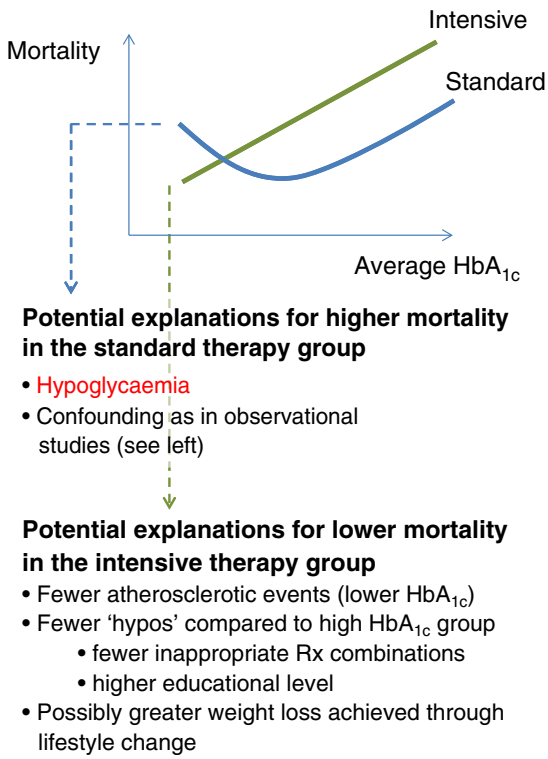

lowering in this trial. Whilst the early reduction in the risk for myocardial infarction is most likely to be attributable to the beneficial effects of metformin, it may be significant (considering the study by Andersson and coworkers [1]) that this early benefit was observed in overweight or obese individuals. However, in longer term follow-up of UKPDS participants, the mortality and macrovascular benefits were observed in all trial participants and with all glucoselowering therapies [21].

More recently, three trials that aimed to normalise $\mathrm{HbA}_{1 \mathrm{c}}$ in older, higher-risk patients, showed no overall cardiovascular benefit associated with more aggressive glucose lowering therapy [22-24]. Although there may have been fewer non-fatal myocardial infarctions with aggressive glucose lowering in the ACCORD trial [25], many clinicians were extremely concerned about the increased mortality risk in the intensive therapy group. The cause of this increased mortality is uncertain, but potential explanations included hypoglycaemia, weight gain or the effects of individual drugs or their combinations. For many clinicians, the most likely culprit has been hypoglycaemia, even though several post hoc analyses of ACCORD data have suggested that this is not the case $[26,27]$.

What is fascinating about the ACCORD data is that the nature of the intervention changed the epidemiological relationship between average $\mathrm{HbA}_{1 \mathrm{c}}$ and mortality (Fig. 1b) [27]. In the standard therapy group this relationship was similar to the U- or the J-shaped relationships seen in some observational studies $[9,12,13,16]$, and we might speculate that the underlying cause of the higher mortality associated with low $\mathrm{HbA}_{1 \mathrm{c}}$ values might be similar (e.g. hypoglycaemia and comorbidity). However in the intensive therapy group, the relationship between $\mathrm{HbA}_{1 \mathrm{c}}$ and mortality was linear and positive [27].
Patients who were easily able to achieve low $\mathrm{HbA}_{1 \mathrm{c}}$ values with intensive therapy experienced the lowest risk of death, even though intensive therapy was harmful overall.

In the Action in Diabetes and Vascular Disease: Preterax and Diamicron Modified Release Controlled Evaluation (ADVANCE) study, severe hypoglycaemia was clearly linked to increased risks for a range of adverse outcomes (CVD, death, microvascular and non-vascular). The authors concluded that comorbid conditions could increase vulnerability to both hypoglycaemia and adverse outcomes in the absence of a direct causal link between the two [28]. In an epidemiological analysis of ADVANCE, non-linear (J-shaped) relationships between average or baseline $\mathrm{HbA}_{1 \mathrm{c}}$ and mortality were suggested both in the standard therapy group and in the intensive therapy group. As the authors were careful to point out, the nature of the relationship between $\mathrm{HbA}_{1 \mathrm{c}}$ and mortality may be different in different populations, it may change over time and it may be modified by other risk factors or therapies [29].

This overview clearly highlights the limitations of using epidemiological data for the purpose of setting clinical $\mathrm{HbA}_{1 \mathrm{c}}$ targets. For example, if we were to use only epidemiological data from the intensive therapy arm of ACCORD, then we might conclude that lower $\mathrm{HbA}_{1 \mathrm{c}}$ values would always be better. But this would ignore the large number of deaths that occurred with intensive glucose lowering in those who had persistently elevated $\mathrm{HbA}_{1 \mathrm{c}}$ values.

So, does the study presented by Andersson and coworkers [1] have any immediate clinical implications? Since these are observational data, it is best viewed as hypothesisgenerating, without influencing immediate clinical care. Decisions about optimal clinical $\mathrm{HbA}_{1 \mathrm{c}}$ targets should be guided mainly by the results of clinical trials involving 
patients randomised to different $\mathrm{HbA}_{1 \mathrm{c}}$ targets and then followed for important clinical outcomes [30]. The recent ADA/EASD position statement appropriately emphasises the importance of additional factors which should influence $\mathrm{HbA}_{1 \mathrm{c}}$ targets set for individual patients. These include patient attitudes and their expected therapeutic involvement, risk of hypoglycaemia, disease duration, life expectancy, the presence of comorbidity (especially CVD), and patient access to resources and support systems [31].

\section{Where do we go from here?}

It may be useful to consider what new research is likely to advance this field. Future studies assessing the relationship between low $\mathrm{HbA}_{1 \mathrm{c}}$ and mortality should aim to collect more comprehensive information about potential confounding factors and perform stratified analyses using this information. Since mortality and CVD event rates are usually low in those with low $\mathrm{HbA}_{1 \mathrm{c}}$ values, a meta-analysis of currently available observational studies, using individual patient-level data, might help to clarify the nature of the relationship between low-range $\mathrm{HbA}_{1 \mathrm{c}}$ and mortality, and determine the patient characteristics that confound the association between low $\mathrm{HbA}_{1 \mathrm{c}}$ values and increased mortality. Similarly, it may be useful to perform a meta-analysis of recent clinical trial data to highlight more patient subgroups (such as those with higher BMI) that might benefit or be harmed by an intensive glucose-lowering regimen. These efforts would be hypothesis-generating and findings would require confirmation in clinical trials.

We need randomised controlled clinical trials to explore the benefits of low $\mathrm{HbA}_{1 \mathrm{c}}$ targets, using agents associated with a low risk of hypoglycaemia and weight gain (metformin and incretin-based therapies) in high-CVD-risk patients with recent-onset type 2 diabetes or non-diabetic hyperglycaemia. Although these clinical trials will be essential, variation in patient characteristics and the number of diabetes therapy combinations available will mean that we will probably never have an appropriate controlled clinical trial to guide clinicians in every possible clinical scenario.

More than ever, clinicians will be expected to integrate the evidence from observational studies and clinical trials, and to combine this with the detailed knowledge of their patients when setting individualised $\mathrm{HbA}_{1 \mathrm{c}}$ targets [31].

Acknowledgements The author would like to thank N. Sattar (University of Glasgow, UK) for critical discussion of the manuscript.

Funding MK Rutter is supported by a HEFCE Clinical Senior Lecturer award.

Duality of interest The author declares that there is no duality of interest associated with this work.
Contribution statement The author was responsible for the conception, design, drafting, revision and approval of the article.

\section{References}

1. Andersson C, van Gaal L, Caterson ID, et al (2012) Relationship between $\mathrm{HbA}_{1 \mathrm{c}}$ levels and risk of cardiovascular adverse outcomes and all-cause mortality in overweight and obese cardiovascular high-risk women and men with type 2 diabetes. Diabetologia. doi:10.1007/s00125-012-2584-3

2. Sarwar N, Gao P, Seshasai SR et al (2010) Diabetes mellitus, fasting blood glucose concentration, and risk of vascular disease: a collaborative meta-analysis of 102 prospective studies. Lancet 375:2215-2222

3. de Vegt F, Dekker JM, Ruhe HG et al (1999) Hyperglycaemia is associated with all-cause and cardiovascular mortality in the Hoorn population: the Hoorn Study. Diabetologia 42:926-931

4. Khaw KT, Wareham N, Luben R et al (2001) Glycated haemoglobin, diabetes, and mortality in men in Norfolk cohort of European Prospective Investigation of Cancer and Nutrition (EPIC-Norfolk). BMJ 322:15-18

5. Selvin E, Coresh J, Golden SH, Brancati FL, Folsom AR, Steffes MW (2005) Glycemic control and coronary heart disease risk in persons with and without diabetes: the atherosclerosis risk in communities study. Arch Intern Med 165:1910-1916

6. Levitan EB, Liu S, Stampfer MJ et al (2008) $\mathrm{HbA}_{1 \mathrm{c}}$ measured in stored erythrocytes and mortality rate among middle-aged and older women. Diabetologia 51:267-275

7. Gerstein HC, Swedberg K, Carlsson J et al (2008) The hemoglobin $\mathrm{A}_{1 \mathrm{c}}$ level as a progressive risk factor for cardiovascular death, hospitalization for heart failure, or death in patients with chronic heart failure: an analysis of the Candesartan in Heart Failure: Assessment of Reduction in Mortality and Morbidity (CHARM) program. Arch Intern Med 168:1699-1704

8. Selvin E, Steffes MW, Zhu H et al (2010) Glycated hemoglobin, diabetes, and cardiovascular risk in nondiabetic adults. N Engl J Med 362:800-811

9. Currie CJ, Peters JR, Tynan A et al (2010) Survival as a function of $\mathrm{HbA}_{1 \mathrm{c}}$ in people with type 2 diabetes: a retrospective cohort study. Lancet 375:481-489

10. Carson AP, Fox CS, McGuire DK et al (2010) Low hemoglobin A1c and risk of all-cause mortality among US adults without diabetes. Circ Cardiovasc Qual Outcomes 3:661-667

11. Eeg-Olofsson K, Cederholm J, Nilsson PM et al (2010) New aspects of $\mathrm{HbAlc}$ as a risk factor for cardiovascular diseases in type 2 diabetes: an observational study from the Swedish National Diabetes Register (NDR). J Intern Med 268:471-482

12. Colayco DC, Niu F, McCombs JS, Cheetham TC (2011) A1C and cardiovascular outcomes in type 2 diabetes: a nested case-control study. Diabetes Care 34:77-83

13. Huang ES, Liu JY, Moffet HH, John PM, Karter AJ (2011) Glycemic control, complications, and death in older diabetic patients: the diabetes and aging study. Diabetes Care 34:1329-1336

14. Kerr D, Partridge H, Knott J, Thomas PW (2011) $\mathrm{HbA}_{1 \mathrm{c}} 3$ months after diagnosis predicts premature mortality in patients with new onset type 2 diabetes. Diabet Med 28:1520-1524

15. Pfister R, Sharp SJ, Luben R, Khaw KT, Wareham NJ (2011) No evidence of an increased mortality risk associated with low levels of glycated haemoglobin in a non-diabetic UK population. Diabetologia 54:2025-2032

16. Aguilar D, Bozkurt B, Ramasubbu K, Deswal A (2009) Relationship of hemoglobin A1C and mortality in heart failure patients with diabetes. J Am Coll Cardiol 54:422-428 
17. Greenfield S, Billimek J, Pellegrini F et al (2009) Comorbidity affects the relationship between glycemic control and cardiovascular outcomes in diabetes: a cohort study. Ann Intern Med 151:854-860

18. Frier BM, Schernthaner G, Heller SR (2011) Hypoglycemia and cardiovascular risks. Diabetes Care 34(Suppl 2):S132-S137

19. Miller ME, Bonds DE, Gerstein HC et al (2010) The effects of baseline characteristics, glycaemia treatment approach, and glycated haemoglobin concentration on the risk of severe hypoglycaemia: post hoc epidemiological analysis of the ACCORD study. BMJ 340:b5444

20. United Kingdom Prospective Diabetes Study Group (1998) Effect of intensive blood-glucose control with metformin on complications in overweight patients with type 2 diabetes (UKPDS 34). UK Prospective Diabetes Study (UKPDS) Group. Lancet 352:854-865

21. Holman RR, Paul SK, Bethel MA, Matthews DR, Neil HA (2008) 10 -year follow-up of intensive glucose control in type 2 diabetes. N Engl J Med 359:1577-1589

22. Gerstein HC, Miller ME, Byington RP et al (2008) Effects of intensive glucose lowering in type 2 diabetes. $\mathrm{N}$ Engl J Med 358:2545-2559

23. Patel A, MacMahon S, Chalmers J et al (2008) Intensive blood glucose control and vascular outcomes in patients with type 2 diabetes. N Engl J Med 358:2560-2572

24. Duckworth W, Abraira C, Moritz T et al (2009) Glucose control and vascular complications in veterans with type 2 diabetes. $\mathrm{N}$ Engl J Med 360:129-139
25. Turnbull FM, Abraira C, Anderson RJ et al (2009) Intensive glucose control and macrovascular outcomes in type 2 diabetes. Diabetologia 52:2288-2298

26. Bonds DE, Miller ME, Bergenstal RM et al (2010) The association between symptomatic, severe hypoglycaemia and mortality in type 2 diabetes: retrospective epidemiological analysis of the ACCORD study. BMJ 340:b4909

27. Riddle MC, Ambrosius WT, Brillon DJ et al (2010) Epidemiologic relationships between $\mathrm{A} 1 \mathrm{C}$ and all-cause mortality during a median 3.4-year follow-up of glycemic treatment in the ACCORD trial. Diabetes Care 33:983-990

28. Zoungas S, Patel A, Chalmers J et al (2010) Severe hypoglycemia and risks of vascular events and death. N Engl J Med 363:1410-1418

29. Zoungas S, Chalmers J, Ninomiya $T$ et al (2012) Association of $\mathrm{HbA}_{1 \mathrm{c}}$ levels with vascular complications and death in patients with type 2 diabetes: evidence of glycaemic thresholds. Diabetologia 55:636-643

30. Rutter MK, Nesto RW (2011) Blood pressure, lipids and glucose in type 2 diabetes: how low should we go? Re-discovering personalized care. Eur Heart J 32:2247-2255

31. Inzucchi SE, Bergenstal RM, Buse JB et al (2012) Management of hyperglycaemia in type 2 diabetes: a patient-centered approach. Position statement of the American Diabetes Association (ADA) and the European Association for the Study of Diabetes (EASD). Diabetologia 55:1577-1596 